\title{
Chest wall toxicity after stereotactic radiation in early lung cancer: a systematic review
}

\author{
I.S. Voruganti MD, ${ }^{*}$ E. Donovan $\mathrm{MD}^{* \dagger}$ C. Walker-Dilks $\mathrm{MLS}^{\ddagger}$ and A. Swaminath $\mathrm{MD}^{\S} \| \#$
}

\begin{abstract}
Background Radiation-induced chest wall pain (CWP) and rib fracture (RF) are late adverse effects after stereotactic body radiation therapy (SBRT) for stage I non-small-cell lung cancer (NSCLC); however, the literature about their incidence and risk factors shows variability. We performed a systematic review to determine the pooled incidence of CWP and RF in the relevant population.
\end{abstract}

Methods A literature search using the PRISMA (Preferred Reporting Items for Systematic Reviews and Meta-Analyses) guidelines considered English publications in MEDLINE and EMBASE from January 1996 to August 2017. Abstracts were screened, followed by full-text review and data extraction.

Results The database searches identified 547 records. Twenty-eight publications comprising 3892 patients met the inclusion criteria. Median reported ages and follow-up durations fell into the ranges 67-82 years and 12-84 months. Prescriptions fell into the range of 40-70 Gy in 3-10 fractions. Despite study heterogeneity, the pooled incidences of CWP and RF were estimated to be $8.94 \%$ and $5.27 \%$ respectively. Nineteen studies reported cWP grade: 58 of 308 patients (18.8\%) experienced grades 3-4 CWP (no grade 5 events reported). Thirteen studies reported RF grade: grades 3-4 RF were observed in 9 of 113 patients (7.96\%). A high chest wall $V_{30}$ was an important predictor of CWP and RF.

Conclusions In patients with stage I NSCLC, rates of CWP and RF after SBRT are low; however, tumour location, accurate toxicity reporting, and dose-fractionation schemes might alter those rates. Prospective correlation with dosimetry and quality of life assessment will further improve the understanding of CWP and RF after SBRT.

Key Words Chest wall pain, rib fracture, stereotactic body radiation therapy, non-small-cell lung cancer, systematic reviews

\section{INTRODUCTION}

Stereotactic body radiation therapy (SBRT) is established as a viable treatment option for patients with stage I nonsmall-cell lung cancer (NSCLC) and is usually indicated in patients deemed ineligible for surgical resection. Even with extended follow-up (beyond 5 years after therapy), SBRT has been associated with excellent rates of local control ${ }^{1}$.

Together with prolonged local control, patients treated with SBRT can, because of the extreme hypofractionation used, experience unique toxicities not usually reported with conventional radiotherapy. The radiation-induced chest wall toxicities (CWTs) of chest wall pain (CWP) and rib fracture (RF) are two examples of unique late adverse effects after hypofractionated SBRT. Chest wall pain can be focal or neuropathic in nature, and mild to moderate in severity; RF can be symptomatic or asymptomatic ${ }^{2}$. Radiation-induced $\mathrm{RF}$ is considered a late toxicity of therapy and typically develops after approximately 6-48 months, occurring either transiently or lasting several weeks or longer ${ }^{3}$. The proposed mechanism of CWP is injury to the peripheral nerves, causing any one or more of paresthesia, hypoesthesia, weakness, and pain. Mild-to-moderate cWP can be treated effectively with narcotics or anti-inflammatory medication.

Currently, despite many reports documenting SBRTinduced CWT, the incidence of, and risk factors for, CWP and 
RF in this population shows variability. There is also lack of clarity about the dosimetric parameters that might increase the risk of CWP and RF after SBRT. Such information would be useful for clinicians for purposes of patient consent, treatment planning, and follow-up guidelines. We therefore performed a systematic review to determine the pooled incidence of CWP and RF in patients with stage I NSCLC treated with SBRT.

\section{METHODS}

\section{Search Strategy}

A comprehensive literature search that followed the PRISMA (Preferred Reporting Items for Systematic Reviews and Meta-Analyses) guidelines was conducted. The MEDLINE and EMBASE databases were queried to obtain English language studies analyzing CWP and RF after SBRT for early-stage NSCLC for the period January 1996 to 22 August 2017. A health research methodologist (CWD) assisted in the development of the search strategy and executed the search. A grey literature search using the Google and Google Scholar search engines, with key terms, was conducted to find conference abstracts, presentations, proceedings, regulatory data, unpublished trial data, government publications, reports, dissertations or theses, patents, and policies and procedures for review. No additional studies were included after review of pertinent studies from the grey literature search. Details about the search strategy can be found in supplementary Appendix 1.

\section{Inclusion Criteria}

Screening of titles and abstracts from the primary search was initially conducted independently by 2 reviewers (ISV, ED), and discrepancies were resolved by a 3rd reviewer (AS). If two or more studies were published using the same cohort of patients, the most recent study that fulfilled the inclusion criteria was kept. Included studies relevant for the review met these criteria:

An early-stage (stage I) primary NSCLC site of radiation therapy (studies that included patients with lung metastases or in which primary could not be parsed out from metastatic disease were excluded; re-irradiation by SBRT for local recurrence was also excluded)

The primary modality of treatment being SBRT

The study type being a randomized controlled trial, a meta-analysis of randomized controlled trials, a prospective study, or a retrospective study (case reports, case series, abstracts, letters, and commentaries were excluded)

Incidence of CWP or RF (or both) reported

Inclusion of 20 or more patients

Publication in the English language

Toxicities scored using the Common Terminology Criteria for Adverse Events, version 3.0 or $4.0^{4,5}$

\section{Data Abstraction and Analysis}

Full-text publication review and data extraction were performed by the primary reviewer (ISV). A weighted analysis of the data was performed by 2 reviewers (ISV, AS). Given the heterogeneity of the studies, a formal meta-analysis could not be performed. Pooled weighted analyses were performed to obtain the incidences of both CWP and RF across all available studies, with the sum of the crude number of RFs (total and totals by grade) and of the crude incidences of CWP (total and totals by grade) divided by the total number of patients included in the analysis who received SBRT for the first time for their lung cancer. The ROBINS-I risk of bias tool was used to assess bias in each study ${ }^{6}$.

\section{CWT Reporting}

To describe the severity of organ toxicity (adverse events) for patients receiving cancer therapy, toxicity data are reported using standardized definitions (Common Terminology Criteria for Adverse Events, version 3.0 or 4.0).

\section{RESULTS}

\section{Search Results}

A PRISMA 2009 flow diagram (Figure 1) summarizes the review process. The initial database search identified 547 records. After exclusion of abstracts, seventy full-text articles were assessed for eligibility. Of those articles, forty-two were excluded because they did not meet the inclusion criteria. Studies were excluded if they included patients who had previously received radiotherapy for lung cancer, who did not have primary lung cancer, or who received SBRT for lung metastases. Studies were also excluded if toxicity was scored using a scale other than the Common Terminology Criteria for Adverse Events, version 3.0 or 4.0.

\section{Study Characteristics}

Table I summarizes characteristics of the included studies and patients. Twenty-eight full-text publications met the inclusion criteria, representing 3892 patients treated with

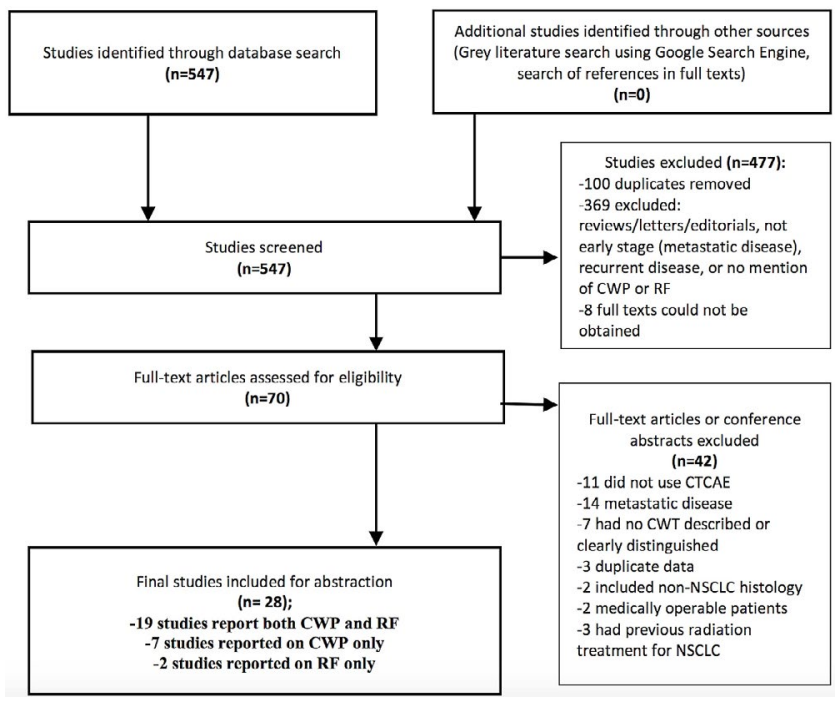

FIGURE 1 PRISMA (Preferred Reporting Items for Systematic Reviews and Meta-Analyses) flow diagram outlining the literature search strategy. $\mathrm{CWP}=$ chest wall pain; $\mathrm{RF}=$ rib fracture; $\mathrm{CTCAE}=$ Common Terminology Criteria for Adverse Events; NSCLC = non-small-cell lung cancer. 
SBRT for primary lung cancer for the first time $\mathrm{e}^{2,3,7-32}$. Dates for the extracted studies reached up to August 2017. Median patient age in the included studies ranged from 67 to 82 years, and median follow-up varied from 12 to 84 months. Studies were mostly retrospective in nature. The number of patients evaluated in each study ranged from 20 to 772 . Doses ranged from 40 Gy to 70 Gy in 3-10 fractions.

Patient characteristics summarized in Table I include sex, T stage, and tumour location and histology. Results across studies were heterogeneous because of differences in grading, tumour location, and the observational nature of the studies. As a result, a formal meta-analysis of the data was not performed, and a weighted pooled analysis of the data was undertaken as described in the Methods section. The ROBINS-I risk of bias tool noted a significantly high risk of bias in most studies because of nonrandomized populations.

\section{CWT Results Across Studies}

Table II summarizes the CWP and RF toxicity grading. The weighted pooled incidence of reported CWP, including all grades, was estimated to be $8.94 \%$, and the pooled incidence of reported $\mathrm{RF}$, including all grades, was estimated to be $5.27 \%$. Across studies, the median time to CWP fell into the range of 3-13 months, and the median time to $\mathrm{RF}$ fell into the range of 3-34.8 months. Nineteen studies reported the grade of CWP toxicity 2,7-12,14-17,19,20,23,25-28,31 (summarized in Table III), with 58 of 308 patients who had graded CWP (18.8\%) experiencing grades $3-4$ pain (no grade 5 events reported). Thirteen studies reported the grade of RF toxicity $2,7,8,10-12,15,20,21,24,26,27,32$ (summarized in Table III), with 9 of 113 patients who had graded RF (7.96\%) experiencing grades 3-4 toxicity $2,10,11,20,24,26$.

\section{SBRT Dosimetry Across Studies}

Table IV summarizes the SBRT dosimetry analysis for twentyeight included studies. Four studies reported specifically on chest wall dosimetry, with the most common parameter being the volume receiving $30 \mathrm{~Gy}$ or more $\left(V_{30}\right)$ in cubic centimetres $^{19,24,28,31}$. Within those studies, a high chest wall $V_{30}$ was found to be an important common predictor of both CWP and RF.

\section{DISCUSSION}

Individual studies have reported the incidence of CWT after SBRT for early-stage NSCLC ${ }^{33}$; however, to our knowledge, the present comprehensive systematic review is the first to examine the pooled incidence of CWP and RF across studies in patients specifically with early-stage NSCLC (excluding patients with lung metastases) treated with SBRT. Because SBRT-related toxicities typically occur late (after 6 months) and can be severe, knowledge about the potential incidence of late side effects is important for guiding the consent process with patients and for ensuring appropriate SBRT planning to minimize the toxicity risk. Based on our review, the overall rates of RF and CWP across studies appear reassuringly low; however, a small but significant proportion of patients with RF and CWP experience significant morbidity, with $7.96 \%$ (RF) and $18.8 \%$ (CWP) reporting
TABLE I Characteristics of 28 studies analyzed

\begin{tabular}{lc}
\hline \multicolumn{1}{c}{ Variable } & Value \\
\hline Study characteristics & \\
\hline Location ( n studies) & United States (14) \\
& Netherlands (5) \\
& Sweden (2) \\
& Japan (2) \\
& Canada (2) \\
& Korea (1) \\
& Multicentre (2) \\
Type ( $n$ studies) & Retrospective (22) \\
& Prospective (4) \\
& Randomized \\
& controlled trials (2) \\
Patient characteristics & \\
\hline Enrolled ( $n$ ) & \\
Per-study range & 3892 \\
Median age range [years (21 studies)] & $20-772$ \\
Sex (n) & $67-82$ \\
Men (21 studies) & 1790 \\
Women (22 studies) & 1580 \\
\hline
\end{tabular}

Tumour characteristics

T Stage $(n)$

T1 (20 studies) 2128

T2 (16 studies) $\quad 607$

Histology (n)

Adenocarcinoma (16 studies) $\quad 968$

Squamous cell carcinoma $\quad 625$

(16 studies)

NOS or other (16 studies)

151

Location (n)

Central (11 studies $\left.{ }^{7-17}\right)$

Peripheral (17 studies $3,7-10,12-23)$

Treatment characteristics

\begin{tabular}{lc}
\hline Total dose (Gy) & $40-70$ \\
\hline Total fractions $(n)$ & $3-10$ \\
\hline Dose per fraction (Gy) & $5-22$ \\
$\begin{array}{l}\text { Most common Rx (total Gy/n } \\
\text { fractions) }\end{array}$ & $60 / 3$ and $60 / 5$ \\
\hline $\begin{array}{l}\text { Median follow-up (months) } \\
\text { Studies stating tumour distance from } \\
\text { chest wall }(n)\end{array}$ & $12-84$ \\
\hline
\end{tabular}

a Pooled analysis of 2 randomized controlled trials (RCTs).

NOS $=$ not otherwise specified

grade 3 or greater toxicity. In patients undergoing surgery (the standard of care for stage I NSCLC), post-thoracotomy pain can occur in approximately $50 \%$ of patients ${ }^{34}$, with $30 \%$ of patients reporting pain after $4-5$ years $^{35}$. Up to $10 \%$ of postsurgical patients experience severe, disabling pain ${ }^{36}$. Thus, in a valid comparison between treatments, the risks 
|

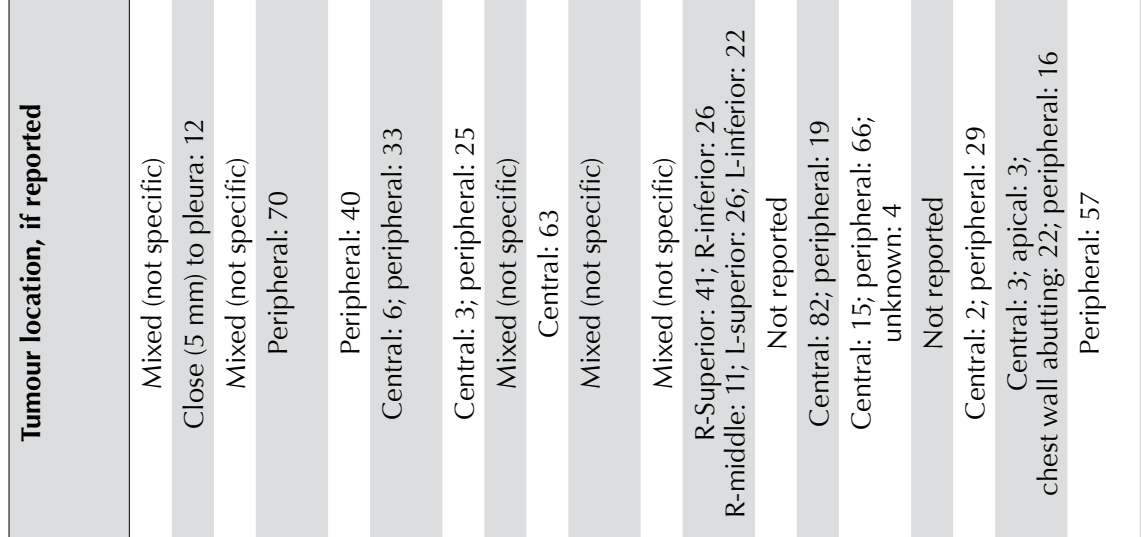

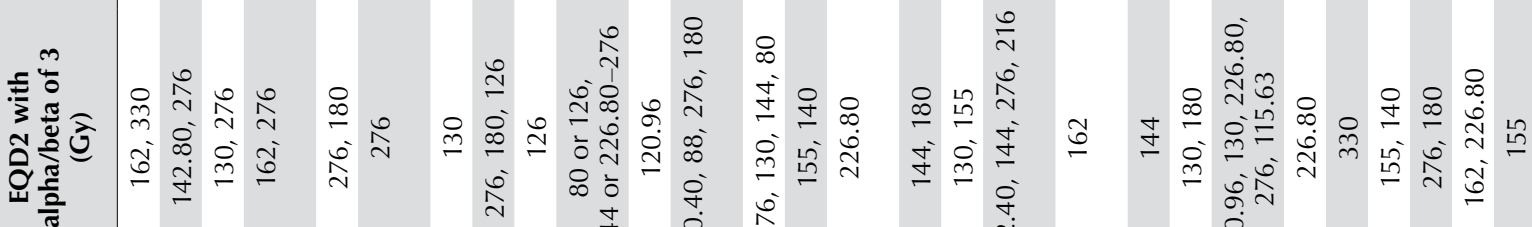
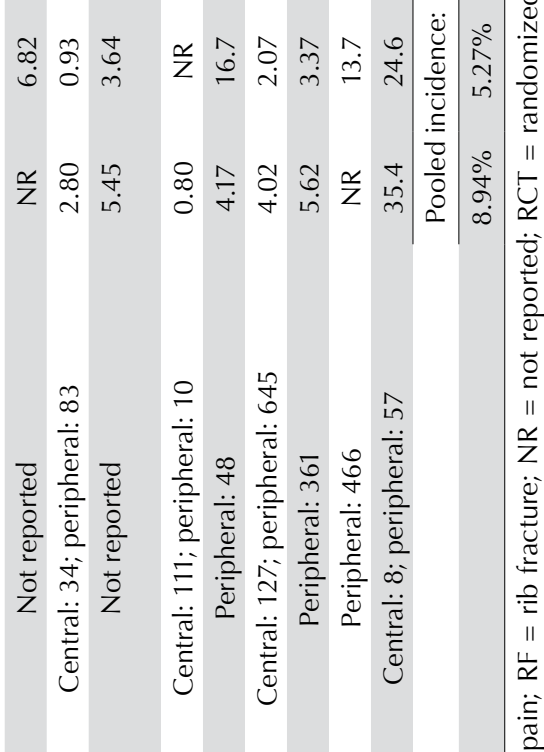
SBRT CHEST WALL TOXICITY IN NSCLC: SYSTEMATIC REVIEW, Voruganti et al.

TABLE III Studies describing the grade of adverse effects

\begin{tabular}{|c|c|c|c|c|c|c|}
\hline \multirow[t]{2}{*}{ Reference } & \multirow{2}{*}{$\begin{array}{l}\text { Total pts } \\
\text { (n) }\end{array}$} & \multirow{2}{*}{$\begin{array}{l}\text { CWP or RF with } \\
\text { reported } \\
\text { toxicity grade }\end{array}$} & \multicolumn{4}{|c|}{ Grade } \\
\hline & & & 1 & 2 & 3 & 4 \\
\hline \multicolumn{7}{|c|}{ Studies $(\mathrm{n}=19)$ describing grade of $C W P$} \\
\hline Baumann et al., $2009^{26}$ & 57 & 13 & \multicolumn{2}{|c|}{11 (9 early, 2 late) } & 2 (early) & - \\
\hline $\begin{array}{l}\text { van der Voort van Zyp } \\
\text { et al., 2009 }\end{array}$ & 70 & 5 & - & - & 5 (1 acute, 4 late) & - \\
\hline $\begin{array}{l}\text { van der Voort van Zyp } \\
\text { et al., } 2010^{16}\end{array}$ & 39 & 3 & - & - & 3 (late) & - \\
\hline Videtic et al., $2010^{17}$ & 26 & 1 & - & 1 (late) & - & - \\
\hline Bongers et al., $2011^{25}$ & 500 & $\begin{array}{c}57 \\
\text { (28 acute, } 29 \text { late) }\end{array}$ & 47 & 10 & - & 4 \\
\hline Haasbeek et al., $2011^{11}$ & 63 & 12 & $\begin{array}{c}7 \\
\text { (3 acute, } 4 \text { late) }\end{array}$ & $\begin{array}{c}3 \\
\text { (1 acute, } 2 \text { late) }\end{array}$ & $\begin{array}{c}2 \\
\text { (1 acute, } 1 \text { late) }\end{array}$ & - \\
\hline Taremi et al., $2012^{2}$ & 46 & $\begin{array}{l}7 \text { without RF, } \\
14 \text { with RF }\end{array}$ & $\begin{array}{l}4 \text { without } R F \text {, } \\
5 \text { with RF }\end{array}$ & $\begin{array}{l}3 \text { without RF, } \\
6 \text { with RF }\end{array}$ & $\begin{array}{l}0 \text { without } R F \text {, } \\
3 \text { with } R F\end{array}$ & - \\
\hline Mutter et al., $2012^{28}$ & 126 & 54 & 19 & 16 (late) & 19 (late) & - \\
\hline Woody et al., $2012^{31}$ & 102 & 20 & 6 & 13 & 1 & - \\
\hline Chang et al., $2014^{9}$ & 101 & 31 & 18 & 13 & - & - \\
\hline Chang et al., $2015^{10}$ & 31 & 3 & - & - & 3 & - \\
\hline Jung et al., $2015^{12}$ & 44 & 2 & 2 (acute) & - & - & - \\
\hline Lindberg et al., $2015^{20}$ & 91 & 4 & - & 2 (early) & 2 (early) & \\
\hline Alite et al., 2016 & 107 & 3 & 3 & - & - & - \\
\hline Bhandari et al., $2016^{27}$ & 55 & 3 & - & 3 (late) & - & - \\
\hline Mancini et al., 2016 14 & 251 & 2 & - & - & 2 (late) & \\
\hline Brooks et al., $2017^{8}$ & 772 & 31 & - & 28 & 3 & - \\
\hline Jumeau et al., $2017^{19}$ & 356 & $\begin{array}{l}11 \text { without RF, } \\
9 \text { with RF }\end{array}$ & - & 18 & 2 & - \\
\hline Sun et al., $2017^{15}$ & 65 & 23 & 15 (late) & 7 (late) & 1 (late) & - \\
\hline TOTAL & 2902 & 308 & $\begin{array}{r}\text { Grades } \\
250\end{array}$ & $\begin{array}{l}-2 \text { CWP: } \\
1.2 \%)\end{array}$ & $\begin{array}{r}\text { Grades } 3-4 \\
58(18.8\end{array}$ & \\
\hline \multicolumn{7}{|c|}{ Studies $(\mathrm{n}=13$ ) describing grade of $R F$} \\
\hline Baumann et al., $2009^{26}$ & 57 & 6 & \multicolumn{2}{|c|}{4 (late) } & \multicolumn{2}{|l|}{2 (1 early, 1 , late) } \\
\hline Haasbeek et al., $2011^{11}$ & 63 & 1 & 0 & 0 & 1 (late) & 0 \\
\hline Taremi et al., $2012^{2}$ & 46 & 17 & 8 & 6 & 3 & - \\
\hline Asai et al., $2012^{24}$ & 116 & 28 & 20 & 7 & 1 & - \\
\hline Chang et al., $2015^{10}$ & 31 & 1 & - & - & 1 & 0 \\
\hline Jung et al., $2015^{12}$ & 44 & 3 & 3 (chronic) & 0 & 0 & 0 \\
\hline Lindberg et al., $2015^{20}$ & 57 & 8 & 0 & $\begin{array}{c}7 \\
\text { (2 early, } 5 \text { late) }\end{array}$ & \multicolumn{2}{|l|}{1 (late) } \\
\hline Yoshitake et al., $2015^{32}$ & 88 & 6 & 0 & 6 & 0 & - \\
\hline Alite et al., 2016 & 107 & 1 & 1 & 0 & 0 & 0 \\
\hline Bhandari et al., $2016^{27}$ & 55 & 2 & 2 & - & - & - \\
\hline Nyman et al., $2016^{21}$ & 48 & 8 & 6 & 2 & 0 & - \\
\hline Brooks et al., $2017^{8}$ & 772 & 16 & - & 16 & 0 & 0 \\
\hline Sun et al., $2017^{15}$ & 65 & 16 & 13 (late) & 3 (late) & 0 & 0 \\
\hline TOTAL & 1549 & 113 & \multicolumn{2}{|c|}{$\begin{array}{c}\text { Grades 1-2 RF: } \\
104(92.04 \%)\end{array}$} & \multicolumn{2}{|c|}{$\begin{array}{l}\text { Grades 3-4 RF: } \\
9(7.96 \%)\end{array}$} \\
\hline
\end{tabular}


TABLE IV Chest wall or rib dosimetry characteristics in 28 studies

\begin{tabular}{|c|c|c|c|c|}
\hline Reference & $\mathrm{CW} V_{30}\left(\mathrm{~cm}^{3}\right)$ & $\begin{array}{l}D_{\max } \text { to ribs } \\
\text { or chest wall }\end{array}$ & $\begin{array}{c}D_{0.5-5 \mathrm{~cm} 3} \text { to } \\
\text { small volume }\end{array}$ & Notes \\
\hline Baumann et al., $2009^{26}$ & & No dosimetric data & & - \\
\hline Collins et al., $2009^{18}$ & & No dosimetric data & & - \\
\hline Stephans et al., $2009^{30}$ & & No dosimetric data & & - \\
\hline $\begin{array}{l}\text { van der Voort van Zyp } \\
\quad \text { et al., 200923 }\end{array}$ & & No dosimetric data & & CWP, RF not reported separately \\
\hline Dunlap et al., $2010^{3}$ & & No dosimetric data & & - \\
\hline $\begin{array}{l}\text { van der Voort van Zyp } \\
\text { et al., } 2010^{16}\end{array}$ & & No dosimetric data & & - \\
\hline Videtic et al., 2010 ${ }^{17}$ & & No dosimetric data & & - \\
\hline Bongers et al., 2011 25 & & No dosimetric data & & $\begin{array}{l}60 \text { Gy in } 3 \text { fractions for T1 lesions not } \\
\text { adjacent to CW; } 60 \text { Gy in } 5 \text { fractions for } \\
\text { T1 lesions showing broad contact with } \\
\text { CW and for all T2 lesions; } 60 \text { Gy in } \\
8 \text { fractions for central lesions. } \\
\text { CW was defined by an expansion of } \\
\text { the lungs with } 2 \mathrm{~cm} \text { in lateral, posterior, } \\
\text { and anterior directions, except in the } \\
\text { direction of the mediastinum }\end{array}$ \\
\hline Haasbeek et al., $2011^{11}$ & & No dosimetric data & & - \\
\hline Taremi et al., $2012^{2}$ & - & - & $\begin{array}{l}\mathrm{D}_{0.5 \mathrm{~cm} 3}>60 \text { Gy: } \\
50 \% \text { RF risk }\end{array}$ & $\begin{array}{l}D_{0.5 \mathrm{~cm} 3} \text { and } V_{25} \text { cross-correlated } \\
\text { for } R F \text { incidence }\end{array}$ \\
\hline Asai et al., $2012^{24}$ & $\begin{array}{l}\geq 1.35 \mathrm{~cm}^{3}: 45.8 \% \mathrm{RF} \\
<1.35 \mathrm{~cm}^{3}: 2.16 \% \mathrm{RF}\end{array}$ & $\begin{array}{l}\geq 42.4 \text { Gy: } 45.8 \% \text { RF; } \\
<42.4 \text { Gy: } 1.43 \% \text { RF }\end{array}$ & - & $\begin{array}{c}D_{\max } \text { and } V_{10}, V_{20}, V_{30} \text {, and } V_{40}- \\
\text { median rib-tumour distance: } 2.0 \mathrm{~cm} \\
\text { (range: } 0.3-6.2 \mathrm{~cm} \text { ) }\end{array}$ \\
\hline Mutter et al., $2012^{28}$ & $V_{30} \geq 70 \mathrm{~cm}^{3}$ & - & - & $\begin{array}{c}\text { A CW volume } \geq 70 \mathrm{~cm}^{3} \text { receiving } 30 \text { Gy } \\
\text { was significantly correlated with grade } 2 \text { or } \\
\text { greater CWP }\end{array}$ \\
\hline Woody et al., $2012^{31}$ & $\begin{array}{c}\text { Modified equivalent } \\
\text { uniform dose, } \\
V_{30}=29 \mathrm{~cm}^{3}\left(0-170 \mathrm{~cm}^{3}\right), \\
\text { and maximum point dose } \\
\text { as predictors }\end{array}$ & - & - & $\begin{array}{l}\text { In the modified equivalent uniform dose } \\
\text { models, } V_{30} \text { and maximum point dose were } \\
\text { significant predictors of CWP }(p<0.0005)\end{array}$ \\
\hline Chang et al., $2014^{9}$ & & No dosimetric data & & - \\
\hline Lucas Jr et al., 2014 ${ }^{13}$ & & No dosimetric data & & - \\
\hline Rosen et al., $2014^{29}$ & & No dosimetric data & & - \\
\hline Chang et al., $2015^{10}$ & & No dosimetric data & & - \\
\hline Jung et al., $2015^{12}$ & & No dosimetric data & & - \\
\hline Lindberg et al., $2015^{20}$ & & No dosimetric data & & - \\
\hline Yoshitake et al., $2015^{32}$ & & No dosimetric data & & - \\
\hline Alite et al., $2016^{7}$ & & No dosimetric data & & - \\
\hline Bhandari et al., $2016^{27}$ & & No dosimetric data & & - \\
\hline Mancini et al., $2016^{14}$ & & No dosimetric data & & - \\
\hline Nyman et al., $2016^{21}$ & & No dosimetric data & & - \\
\hline Brooks et al., $2017^{8}$ & & No dosimetric data & & - \\
\hline Jumeau et al., $2017^{19}$ & $\begin{array}{c}V_{30}<30 \mathrm{~cm}^{3} \text { (3 fractions) } \\
\text { vs. } \\
\left.V_{30}>30 \mathrm{~cm}^{3} \text { ( } 5 \text { fractions }\right)\end{array}$ & $\begin{array}{c}\mathrm{BED}_{3}: 522 \text { Gy }(\mathrm{CWT}) \\
\text { vs. } \\
401 \text { Gy (no CWT) }\end{array}$ & $\begin{array}{c}D_{1 \mathrm{~cm} 3:} 411 \text { Gy }(\mathrm{CWT}) \\
\text { vs. } \\
388 \text { Gy (no CWT) } \\
\left(\mathrm{BED}_{3}\right)\end{array}$ & - \\
\hline Stam et al., $2017^{22}$ & - & $\begin{array}{l}<207 \text { Gy vs. }>452 \text { Gy: } \\
\text { TD } 5 \% \text { vs. TD } 50 \% \text { RF }\end{array}$ & $\begin{array}{l}D_{0.5 \mathrm{~cm} 3,} D_{2 \mathrm{~cm} 3} \text { were } \\
\text { predictors of RF }\end{array}$ & $\begin{array}{l}D_{\max } \text { EQD2 }<225 \text { Gy and }<475 \text { Gy } \\
\text { correlated with RF of }<5 \% \text { and }<50 \% \\
\text { respectively at } 26 \text { months }\end{array}$ \\
\hline Sun et al., $2017^{15}$ & & No dosimetric data & & $\begin{array}{l}\text { CWP, RF, plexopathy proportions mentioned, } \\
\text { but no dose-volume correlation given }\end{array}$ \\
\hline
\end{tabular}

$V n=$ absolute volume receiving $\geq n$ Gy; $D_{\max }=$ maximum dose; $D_{0.5-5 \mathrm{~cm} 3}=$ dose to $0.5-5 \mathrm{~cm}^{3} ; \mathrm{CWP}=$ chest wall pain; RF = rib fracture; $C W=$ chest wall; $\mathrm{BED}_{3}=$ biologically effective dose to normal tissue expressed for an alpha/beta ratio of $3 \mathrm{~Gy}$; CWT = chest wall toxicity; TD5\% = dose with 5\% complications; TD50\% = dose with 50\% complications; EQD2 = equivalent total dose in 2 Gy fractions. 
of CWP and RF after radiation appear fairly modest compared with post-thoracotomy pain after surgery; however, further prospective comparisons between those modalities will be required to validate our findings.

Despite the observed low rates of CWP and RF, our analysis also demonstrated significant variability across studies in terms of dose-fractionation regimens, tumour location, and accurate reporting of toxicities and dosimetry. The definitions of "acute" and "late" toxicity with respect to RF and CWP were also variable across studies. Specific to dosimetry, we found that the $V_{30}$ (and perhaps maximum dose avoidance within the chest wall) might be an important parameter to evaluate, but the exact constraints that would lead to increased risk are still unclear. Further, the variation in dose-fractionation across studies is not accounted for.

In addition to the total dose delivered, the dose per fraction contributes to the biologic effect of radiation on both tumour and normal tissue. According to Bongers et $a l .{ }^{25}$, it might be argued that doses should be converted to a linear quadratic model, and yet most studies did not limit their prescriptions to one common scheme ${ }^{37}$. Furthermore, it was difficult to parse out the proportion of patients with peripheral compared with central tumours in each study, and many centres used adapted dose-fractionation schedules for tumours abutting the chest wall. Generally, it has been suggested that the planning target volume and the distance from tumour to chest wall correlate with postSBRT $\mathrm{CWT}^{33}$. As a result, it could be argued that the rates of CWP and RF are underestimated because of those variables.

Another factor affecting dosimetry could be the method of chest wall delineation. Whether only the ribs or the entire chest wall (including intercostal musculature) was delineated was not clear across studies; that uncertainty might influence the dosimetric analysis of CWP and RF, and might provide different results across studies with respect to relevant values when evaluating chest wall dose constraints.

Finally, older studies using less-conformal techniques tended to use SBRT to treat larger tumour volumes ${ }^{38-47}$. Newer approaches using conformal techniques such as volumetric modulated arc therapy and intensity-modulated radiotherapy-and more modern radiotherapy planning algorithms - might be able to further reduce the dose to organs at risk, such as the chest wall ${ }^{48}$ and cannot be accounted for in this review.

Despite the foregoing issues, we believe that, based on this review, some minimum standards for chest wall dosimetry can be applied, including $V_{30}$ and ensuring that the maximum dose within the planning target volume is outside the rib or chest wall contour. However, those factors will have to be prospectively evaluated to establish their relationship with late CWP and $\mathrm{RF}$, especially with variation in dose-fractionation regimens. Two currently open randomized trials in lung SBRT, the Ontario Clinical Oncology Group LUSTRE trial ${ }^{49}$ and the VALOR study (see NCT02984761 at https://ClinicalTrials.gov/) both have chest wall dosimetry limits. The LUSTRE trial (SBRT doses of $48 \mathrm{~Gy}$ in 4 fractions or $60 \mathrm{~Gy}$ in 8 fractions) mandates that the ribs be contoured (not the entire chest wall) and suggests dose-volume limits for $V_{40-50}$ of less than $5 \mathrm{~cm}^{3}$ and a maximum point dose of 50-60 Gy (depending on the fractionation chosen). In the VALOR trial, which is comparing SBRT (54 Gy in 3 fractions,
56 Gy in 4 fractions, or 57.5 Gy in 5 fractions) with surgical resection, ribs and chest wall (including musculature) are both to be contoured. Rib dose-volume limits are $D_{5 \mathrm{~cm} 3}$ less than 40-45 Gy and a maximum point dose of 50-57 Gy; and chest wall limits are $D_{30 \mathrm{~cm}}$ less than 30 Gy and a maximum point dose of 56.7-60.4 Gy, again depending on the fractionation chosen [Moghanaki D (VALOR principal investigator). Personal communication, 2019]. The toxicity outcomes of those trials with respect to late CWP and RF (particularly in the VALOR trial's comparison with surgery) will provide greater knowledge about the dose-toxicity relationship in a prospective fashion.

Another factor potentially influencing rates of CWP and $\mathrm{RF}$ is the accurate reporting of those toxicities after SBRT. Given that most of the studies included in the present review were retrospective, it is difficult to know if the CWP and RF reporting is correct, especially if the aim of the particular study was not specifically evaluating those endpoints. In retrospective studies, grading toxicity is also very difficult unless events were documented clearly as they arose. Nonetheless, it is reassuring that most patients reported only minimal-grade ( 1 or 2 ) CWP after SBRT. Still, it is important not to dismiss the more severe toxicity experienced by some patients and also the risk factors-including age, sex, body mass index, comorbidities, smoking, and osteoporosisthat might increase a patient's risk of post-SBRT CWP and RF. Those risk factors should be considered in conjunction with dosimetric parameters during the SBRT planning process.

Despite the fact that we were evaluating a relatively homogeneous population (patients with stage I NSCLC, excluding patients with lung metastases), we were unfortunately unable to perform a meta-analysis of the available literature. First, the present work is a systematic review and pooled analysis based on observational studies. When combining such studies, heterogeneity of populations, designs, and outcomes can occur and influence the pooled estimates. However, when no studies with adequately large sample sizes are available, a systematic review and pooled analysis of observational studies might still be a valid method of assessment, providing useful evidence to inform the decision about whether more evidence is needed. Second, our analysis is limited by accuracy in the reporting of patient characteristics, tumour location, dose-fractionation schemes, and toxicity reporting as already described, which can affect the pooled toxicity rate. Third, lack of consensus with respect to dose-fractionation regimens across the studies makes it challenging to interpret the findings and thus perform a meta-analysis or pooled analysis of the data. Furthermore, most studies were deemed to have a significantly high risk of bias because of nonrandomized populations, and thus overall evaluation of studies was heavily biased, further limiting our ability to conduct a formal meta-analysis.

Future directions beyond this review would include careful prospective documentation and reporting of patient and dosimetric factors influencing CWP and RF after SBRT. Such documentation would facilitate data pooling such that robust multivariable normal-tissue complication probability models could be developed. Quality of life in patients affected by CWP and RF must also be assessed, as must the use of medications and narcotics and the duration of their use. In turn, clinicians might be better equipped 
to inform patients of the risk of SBRT-induced CWTs and to adapt treatments to minimize the risks.

\section{CONCLUSIONS}

Results from the present review demonstrate low rates of CWP and RF after SBRT in a large variety of patients with stage I NSCLC. However, significant heterogeneity was evident in tumour location, accurate reporting of toxicity, and dose-fractionation schemes, which could relatively increase or decrease those rates. Thus, it is important that authors fully document the characteristics of study populations. Consistency in toxicity grading scales should also be maintained, and the grade of toxicity should be clearly documented, including distinguishing between symptomatic clinically relevant and asymptomatic radiation-induced RF. Differences in organs-at-risk delineation might also have contributed to different outcomes. Nonetheless, despite the limitations of the present systematic review and pooled analysis inherent to the included literature, this report provides a valuable estimate of the incidence of CWP and RF toxicity after SBRT, identifies potential high-risk dosimetric factors, and increases knowledge about this topic that can be further validated in future prospective and comparative trials.

\section{CONFLICT OF INTEREST DISCLOSURES}

We have read and understood Current Oncology's policy on disclosing conflicts of interest, and we declare the following interests: AS, ISV, and CWD have no known conflicts of interest associated with this publication. ED is funded by an Accuray Incorporated grant, with no relation to the present research.

\section{AUTHOR AFFILIATIONS}

*Department of Radiation Oncology, University of Toronto, Toronto; ${ }^{\dagger}$ Odette Cancer Centre, Sunnybrook Health Sciences Centre, Toronto; ${ }^{\ddagger}$ Program in Evidence-Based Care, McMaster University, Hamilton; ${ }^{\S} J u r a v i n s k i$ Cancer Centre at Hamilton Health Sciences, Hamilton; and "Department of Oncology, McMaster University, Hamilton, ON.

\section{REFERENCES}

1. Timmerman RD, Hu C, Michalski J, et al. Long-term results of RTOG 0236: a phase II trial of stereotactic body radiation therapy (SBRT) in the treatment of patients with medically inoperable stage I non-small cell lung cancer [abstract 56]. Int J Radiat Oncol Biol Phys 2014;90 (suppl):S30.

2. Taremi M, Hope A, Lindsay P, et al. Predictors of radiotherapy induced bone injury (RIBI) after stereotactic lung radiotherapy. Radiat Oncol 2012;7:159.

3. Dunlap NE, Larner JM, Read PW, et al. Size matters: a comparison of $\mathrm{T} 1$ and $\mathrm{T} 2$ peripheral non-small-cell lung cancers treated with stereotactic body radiation therapy (SBRT). J Thorac Cardiovasc Surg 2010;140:583-9.

4. Trotti A, Colevas AD, Setser A, et al. CTCAE v3.0: development of a comprehensive grading system for the adverse effects of cancer treatment. Semin Radiat Oncol 2003;13:176-81.

5. United States, Department of Health and Human Services, National Institutes of Health, National Cancer Institute (NCI). Common Terminology Criteria for Adverse Events (CTCAE). Ver. 4.0. Bethesda, MD: NCI; 2010.

6. Sterne JA, Hernán MA, Reeves BC, et al. ROBINS-I: a tool for assessing risk of bias in non-randomised studies of interventions. BMJ 2016;355:i4919.
7. Alite F, Stang K, Balasubramanian N, et al. Local control dependence on consecutive vs. nonconsecutive fractionation in lung stereotactic body radiation therapy. Radiother Oncol 2016;121:9-14.

8. Brooks ED, Sun B, Zhao L, et al. Stereotactic ablative radiation therapy is highly safe and effective for elderly patients with early-stage non-small cell lung cancer. Int JRadiat Oncol Biol Phys 2017;98:900-7.

9. Chang JY, Li QQ, Xu QY, et al. Stereotactic ablative radiation therapy for centrally located early stage or isolated parenchymal recurrences of non-small cell lung cancer: how to fly in a “no fly zone." Int J Radiat Oncol Biol Phys 2014;88:1120-8.

10. Chang JY, Senan S. Paul MA, et al. Stereotactic ablative radiotherapy versus lobectomy for operable stage I non-small-cell lung cancer: a pooled analysis of two randomised trials. Lancet Oncol 2015;16:630-7.

11. Haasbeek CJA, Lagerwaard FJ, Slotman BJ, Senan S. Outcomes of stereotactic ablative radiotherapy for centrally located early-stage lung cancer. J Thorac Oncol 2011;6:2036-43.

12. Jung IH, Song SY, Jung J, et al. Clinical outcome of fiducial-less CyberKnife radiosurgery for stage I non-small cell lung cancer. Radiat Oncol J 2015;33:89-97.

13. Lucas JT Jr, Kuremsky JG, Soike M, et al. Comparison of accelerated hypofractionation and stereotactic body radiotherapy for stage 1 and node negative stage 2 non-small cell lung cancer (NSCLC). Lung Cancer 2014;85:59-65.

14. Mancini BR, Park HS, Harder EM, et al. Elderly patients undergoing SBRT for inoperable early-stage NSCLC achieve similar outcomes to younger patients. Lung Cancer 2016;97:22-7.

15. Sun BB, Brooks ED, Komaki RU, et al. 7-Year follow-up after stereotactic ablative radiotherapy for patients with stage I non-small cell lung cancer: results of a phase 2 clinical trial. Cancer 2017;123:3031-9.

16. van der Voort van Zyp NC, Prévost JB, van der Holt B, et al. Quality of life after stereotactic radiotherapy for stage I non-small-cell lung cancer. Int J Radiat Oncol Biol Phys 2010;77:31-7.

17. Videtic GMM, Stephans K, Reddy C, et al. Intensity-modulated radiotherapy-based stereotactic body radiotherapy for medically inoperable early-stage lung cancer: excellent local control. Int J Radiat Oncol Biol Phys 2010;77:344-9.

18. Collins BT, Vahdat S, Erickson K, et al. Radical CyberKnife radiosurgery with tumor tracking: an effective treatment for inoperable small peripheral stage I non-small cell lung cancer. J Hematol Oncol 2009;2:1.

19. Jumeau R, Filion E, Bahig H, et al. A dosimetric parameter to limit chest wall toxicity in SABR of NSCLC. Br J Radiol 2017;90:20170196.

20. Lindberg K, Nyman J, Riesenfeld Kallskog V, et al. Long-term results of a prospective phase II trial of medically inoperable stage I NSCLC treated with SBRT-the Nordic experience. Acta Oncol 2015;54:1096-104.

21. Nyman J, Hallqvist A, Lund JA, et al. SPACE-a randomized study of SBRT vs conventional fractionated radiotherapy in medically inoperable stage I NSCLC. Radiother Oncol 2016;121:1-8.

22. Stam B, van der Bijl E, Peulen H, Rossi MMG, Belderbos JSA, Sonke JJ. Dose-effect analysis of radiation induced rib fractures after thoracic SBRT. Radiother Oncol 2017;123:176-81.

23. van der Voort van Zyp NC, Prévost JB, Hoogeman MS, et al. Stereotactic radiotherapy with real-time tumor tracking for non-small cell lung cancer: clinical outcome. Radiother Oncol 2009;91:296-300.

24. Asai KS, Shioyama Y, Nakamura K, et al. Radiation-induced rib fractures after hypofractionated stereotactic body radiation therapy: risk factors and dose-volume relationship. Int J Radiat Oncol Biol Phys 2012;84:768-73. 
25. Bongers EM, Haasbeek CJA, Lagerwaard FJ, Slotman BJ, Senan S. Incidence and risk factors for chest wall toxicity after risk-adapted stereotactic radiotherapy for early-stage lung cancer. J Thorac Oncol 2011;6:2052-7.

26. Baumann P, Nyman J, Hoyer M, et al. Outcome in a prospective phase II trial of medically inoperable stage I non-small-cell lung cancer patients treated with stereotactic body radiotherapy. J Clin Oncol 2009;27:3290-6.

27. Bhandari RP, Stanford JD, Packianathan S, et al. Stereotactic body radiation therapy for stage I non-small cell lung cancer: a retrospective, single-centerstudy of 55 patients. Oncology2016; 91:194-204.

28. Mutter RW, Liu F, Abreu A, Yorke E, Jackson A, Rosenzweig KE. Dose-volume parameters predict for the development of chest wall pain after stereotactic body radiation for lung cancer. Int J Radiat Oncol Biol Phys 2012;82:1783-90.

29. Rosen LR, Fischer-Valuck BW, Katz SR, et al. Helical imageguided stereotactic body radiotherapy (SBRT) for the treatment of earlystage lung cancer: a single-institution experience at the Willis-Knighton Cancer Center. Tumori 2014; $100: 42-8$

30. Stephans KL, Djemil T, Reddy CA, et al. A comparison of two stereotactic body radiation fractionation schedules for medically inoperable stage I non-small cell lung cancer: the Cleveland Clinic experience. J Thorac Oncol 2009;4:976-82.

31. Woody NM, Videtic GMM, Stephans KL, Djemil T, Kim Y, Xia P. Predicting chest wall pain from lung stereotactic body radiotherapy for different fractionation schemes. Int J Radiat Oncol Biol Phys 2012;83:427-34.

32. Yoshitake T, Nakamura K, Shioyama, Y, etal. Stereotactic body radiation therapy for primary lung cancers clinically diagnosed without pathological confirmation: a single-institution experience. Int J Clin Oncol 2015;20:53-8.

33. Bongers E, Haasbeek CJA, Lagerwaard FJ, Slotman BJ, Senan S. Predictors of chest wall toxicity following risk-adapted stereotactic radiotherapy in 500 patients treated for early stage lung cancer [abstract 1013]. Int J Radiat Oncol Biol Phys 2011;81(suppl):S162.

34. Rogers ML, Duffy JP. Surgical aspects of chronic postthoracotomy pain. Eur J Cardiothorac Surg 2000;18:711-16.

35. Karmakar MK, Ho AM. Postthoracotomy pain syndrome. Thorac Surg Clin 2004;14:345-52.

36. Kehlet H, Jensen TS, Woolf CJ. Persistent postsurgical pain: risk factors and prevention. Lancet 2006;367:1618-25.

37. Stephans K, Woody N, Djemil T, Tizora N, Xia P, Videtic G. Stereotactic body radiotherapy (SBRT) for central lung lesions: treating beyond RTOG 0813 parameters [abstract 158]. Int J Radiat Oncol Biol Phys 2011;81(suppl):S80.
38. Appel S, Lawrence YR, Goldstein J, et al. Stereotactic ablative body radiation for stage I lung cancer in Israel: a retrospective single-center report. Isr Med Assoc J 2017;19:39-43.

39. Coroller TP, MaK RH, Lewis JH, et al. Low incidence of chest wall pain with a risk-adapted lung stereotactic body radiation therapy approach using three or five fractions based on chest wall dosimetry. PLoS One 2014;9:e94859.

40. Cuaron JJ, Yorke ED, Foster A, et al. Stereotactic body radiation therapy for primary lung cancers $>3$ centimeters. $J$ Thorac Oncol 2013;8:1396-1401.

41. Davis JN, Medbery C, Sharma S, et al. Stereotactic body radiotherapy for centrally located early-stage non-small cell lung cancer or lung metastases from the Rssearch patient registry. Radiat Oncol 2015;10:113.

42. Nagata Y, Hiraoka M, Shibata T, et al. Prospective trial of stereotactic body radiation therapy for both operable and inoperable T1N0M0 non-small cell lung cancer: Japan Clinical Oncology Group Study JCOG0403. Int J Radiat Oncol Biol Phys 2015;93:989-96.

43. Woody NM, Stephans KL, Djemil T, Videtic GMM. Stereotactic body radiotherapy (SBRT) for lung lesions $>4 \mathrm{~cm}$ : safety and efficacy [abstract 2819]. Radiat Oncol 2011;81(suppl):S603-4.

44. Fritz P, Kraus HJ, Blaschke T, et al. Stereotactic, high singledose irradiation of stage I non-small cell lung cancer (NSCLC) using four-dimensional CT scans for treatment planning. Lung Cancer 2008;60:193-9.

45. Hallqvist A, Lund J, Brustugun O, et al. The SPACE study: a randomized phase II trial comparing SBRT and 3DCRT in stage I NSCLC patients; final analysis including HRQL [abstract ORAL19.01]. J Thorac Oncol 2015;10 (suppl 2):S209.

46. Ochiai S, Yamakado K, Kodama H, et al. Comparison of therapeutic results from radiofrequency ablation and stereotactic body radiotherapy in solitary lung tumors measuring $5 \mathrm{~cm}$ or smaller. Int J Clin Oncol 2015;20:499-507.

47. Tekatli H, Haasbeek N, Dahele M, et al. Outcomes of hypofractionated high-dose radiotherapyin poor-risk patients with "ultracentral" non-small cell lung cancer.JThorac Oncol2016; 11:1081-9.

48. Seppala J, Suilamo S, Kulmala J, Mali P, Minn H. A dosimetric phantom study of dose accuracy and build-up effects using IMRT and RapidArc in stereotactic irradiation of lung tumours. Radiat Oncol 2012;7:79.

49. Swaminath A, Wierzbicki M, Parpia S, et al. Canadian phase III randomized trial of stereotactic body radiotherapy versus conventionally hypofractionated radiotherapy for stage I, medically inoperable non-small-cell lung cancer-rationale and protocol design for the Ontario Clinical Oncology Group (OCOG)-LUSTRE trial. Clin Lung Cancer 2017;18:250-4. 